(c) 2018. This manuscript version is made available under the CC-BY-NC-ND 4.0 license http:// creativecommons.org/licenses/by-nc-nd/4.0/

\title{
An international study of the quality of life of adult patients treated with home parenteral nutrition
}

Janet P. Baxter ${ }^{\mathrm{a}}$, Peter P. Fayers ${ }^{\mathrm{b}}$, Federico Bozzettic ${ }^{\mathrm{c}}$, Darlene Kelly ${ }^{\mathrm{d}}$, Francisca Joly ${ }^{\mathrm{e}}$, Jon Shaffer ${ }^{f}$, Getty Huisman-de Waal' ${ }^{\mathrm{g}}$, Geert Wanten ${ }^{\mathrm{g}}$, Cora Jonkers ${ }^{\mathrm{g}}$, Christina Cuerda ${ }^{\mathrm{h}}$, Paul

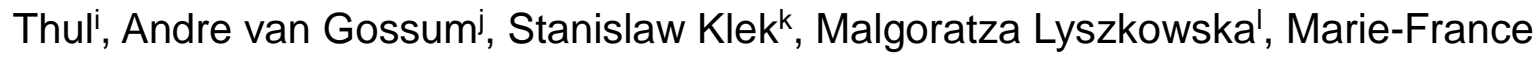
Boudreault $^{\mathrm{m}}$, Alain Gilbert ${ }^{\mathrm{m}}, \mathrm{P}$ Manon Jobin ${ }^{\mathrm{m}}$, Michael Staun ${ }^{\mathrm{n}}$, Lyn Gillanders ${ }^{\mathrm{o}}$, Alastair Forbes $^{p}$, Margie O'Callaghan ${ }^{q}$, Marion O'Connor ${ }^{r}$, Linda Santarpias ${ }^{\mathrm{s}}$, Pilar Gomez Enterria ${ }^{\mathrm{t}}$, Daniele Giardiello ${ }^{\mathrm{u}}$, Cinzia Brunelliv,w, Luigi Mariani ${ }^{\mathrm{u}}$, and Loris Pironix ${ }^{\mathrm{x}}$, Home Artificial Nutrition and Chronic Intestinal Failure special interest group of the European Society for Clinical Nutrition and Metabolism (ESPEN).

${ }^{a}$ Department of Nutrition and Dietetics, Kings Cross Hospital, Dundee, UK, ${ }^{b}$ Department of Public Health, University of Aberdeen, UK, cSurgeon and oncologist, Milan, Italy, dOley Foundation for Home Parenteral and Enteral Nutrition, Albany, New York, USA, e'Centre for Gastroenterology and Nutrition Support, Hôpital Beaujon, Paris, fIntestinal Failure Unit, Salford Royal Hospital, Manchester, UK, ${ }^{g}$ Radboud University Nijmegen Medical Centre, Amsterdam, The Netherlands, hHospital General Universitario Gregorio, Maranon, Madrid, Spain, 'Charité University Hospital, Berlin, Germany, 'Medico-Surgical Department of Gastroenterology, Hôpital Erasme, Brussels, Belgium, kGeneral and Oncology Surgery Unit, Intestinal Failure Center, Stanley Dudrick's Memorial Hospital, Skawina, Poland, 'The Children's Memorial Hospital, Warsaw, Poland, mDepartment of Surgery, Centre Hospitalier Universitaire de Québec, Canada, nDepartment of Gastroenterology, 
Rigshospitalet, Denmark, ${ }^{\circ}$ Nutrition Services, Auckland City Hospital, New Zealand, ${ }^{\mathrm{p}}$ Norwich Medical School, University of East Anglia, Norwich, UK, ${ }^{q}$ Flinders Medical Centre, Bedford Park, Australia, 'Nutrition and Dietetics, John Radcliffe Hospital, Oxford, UK, ${ }^{5}$ Clinical Nutrition and Internal Medicine, Department of Clinical and Experimental Medicine, Federico II University, Naples, Italy, ${ }^{t}$ Hospital Central, de Asturias, Oviedo, Spain, "Unit of Medical Statistics, Biometry, Bioinformatics, Fondazione IRCCS Istituto Nazionale dei Tumori, Milan, Italy; vPalliative Care, Pain Therapy and Rehabilitation Unit, Fondazione IRCCS Istituto Nazionale dei Tumori, Milano, Italy; 'European Palliative Care Research Centre (PRC), Department of Cancer Research and Molecular Medicine, Faculty of Medicine, Norwegian University of Science and Technology (NTNU), Trondheim, Norway, ${ }^{\times}$Centre for Chronic Intestinal Failure, Department of Digestive System, St. Orsola-Malpighi Hospital, University of Bologna, Italy.

Short title: Quality of life in HPN.

Address for correspondence: $\quad$ Dr Janet P. Baxter,

Department of Nutrition and Dietetics,

Kings Cross Hospital,

Dundee, UK

janetbaxter@nhs.net

+44 1382596993 
Keywords: Home parenteral nutrition; quality of life; patient reported outcomes; intestinal failure. 


\section{Abstract}

Background and aims: Home parenteral nutrition-quality of life (HPN-QOL $\left.{ }^{\odot}\right)$ is a selfassessment tool for the measurement of QOL in patients on HPN. The aims of this study were: to re-assess the basic psychometric properties of the $\mathrm{HPN}-\mathrm{QOL}^{\odot}$ in a multinational sample of adult patients; to provide a description of QOL dimensions by short and long HPN treatment duration; to explore clinical factors potentially associated to QOL scores.

Methods: Patients ( $n=699)$ from 14 countries completed the HPN-QOL ${ }^{\odot}$. The questionnaires were analysed to evaluate data completeness, convergent /discriminant validity and internal-consistency reliability. The association of overall QOL and HPN treatment duration as well as other clinical factors were investigated using multivariable linear regression models.

Results: The analysis of the multitrait-scaling and internal consistency indicates a good fit with the questionnaire structure for most items. Item discriminant validity correlation was satisfactory and psychometric evaluation of the $\mathrm{HPN}-\mathrm{QOL}^{\odot}$ in the different English, French and Italian language patient sub-groups confirmed psychometric equivalence of the three questionnaire versions. The results of the multivariable linear regression showed that QOL scores were significantly associated with HPN duration (better in long-term), underlying disease (better in Crohn's disease and mesenteric ischemia) and living status (worse in living alone) and, after adjusting for the other factors, with the number of days of HPN infusion per week.

Conclusions: The HPN-QOL ${ }^{\odot}$, is a valid tool for measurement of QOL in patients on HPN, to be used in the clinical practice as well as in research. 


\section{Introduction}

Intestinal failure is defined as "the reduction of gut function below the minimum necessary for the absorption of macronutrients and/or water and electrolytes, such that intravenous supplementation is required to maintain health and/or growth" (1). Home parenteral nutrition (HPN) is the primary therapy of chronic intestinal failure (CIF) (2). The main aims of HPN are to increase long term survival of patients who may otherwise die of malnutrition or dehydration or should otherwise be confined to hospital and, consequently, to improve, quality of life (QOL) and to allow socio-economic rehabilitation (3). Although patients on HPN may not achieve complete return to normality, scores can improve compared to preHPN (4).

Although HPN is a life-saving therapy for patients with CIF, it does involve the infusion of nutrients into a central vein, and can radically change the life of patients who may be faced with on-going symptoms of the underlying condition but also live a complex, technologydependent lifestyle (5). It is a time-consuming, invasive therapy used in patients who often have physical problems and who have to face many psychological difficulties as well. Anxiety and fear are common reactions to the threat of potentially life-threatening complications of treatment such as severe infection, thrombosis and liver failure (6), which realistically can still occur. Depression, anger, negative self-image and social limitations are frequently reported. Depression has been seen in up to 65\% of patients on HPN and may have serious consequences for their therapy as it has been shown to lead to less careful catheter care and social impairment in 55\% (7). All of these factors may impact on QOL. Severe fatigue has been reported as one of the most frequent complaints - in up to $63 \%$ of HPN patients (8), which in turn consistently affect daily activities such as work and leisure. 
In 2012, the period prevalence of HPN in 16 European countries was estimated to range from 3.25 to 66 patients per million of the population (9). The most common indication for HPN in adults is short bowel arising from underlying diseases such as mesenteric ischemia and Crohn's disease; motility disorders and bowel obstruction due to cancer (7). About $60-79 \%$ of patients in USA and Europe receiving HPN survive for five years or more. At 10 years $84 \%$ are still dependent on HPN and a significant number live 20 years or longer (8-14). In 2009 ESPEN published guidelines for the use of HPN in adults (15) and recognised the lack of studies describing QOL in HPN patients using disease-specific tools; it was noted that measurement of QOL should be patient-based rather than the clinician's perspective.

The HPN-QOL ${ }^{\circ}$, a self-assessment tool for measurement of QOL in patients on HPN, was originally devised within the Home Artificial Nutrition and Chronic Intestinal Failure (HAN\&CIF) special interest group of the European Society for Clinical Nutrition and Metabolism (ESPEN). It underwent psychometric validation in a small sample of English patients and was then translated into Danish, Dutch, French, German, Italian, Polish and Spanish to enable international use (16).

Hence there is the need to assess the basic psychometric performance of the questionnaire in a larger number of patients and with translations into other languages, as well as to provide a description of QOL dimensions in a sample of patients from different European countries. Moreover it was deemed interesting to explore factors that are significantly correlated with patterns/items of QOL.

The aims of the present study are:

1. to re-assess basic psychometric properties of the $\mathrm{HPN}-\mathrm{QOL}^{\odot}$ in a multinational sample and explore differences across the three most widely-spoken languages in our sample: English, French and Italian; 
2. to provide a description of QOL dimensions in a sample of international patients, stratified by short and long HPN treatment duration;

3. to explore clinical factors associated with reported QOL. 


\section{Methods}

\section{Study design}

This is a cross-sectional observational multicentre study promoted by the ESPEN HAN\&CIF working group in fourteen European, North American and Australian countries. The research was also supported by the Scientific Committee of ESPEN which assigned a grant to the principal investigator (JB) of the study. Adult patients were recruited from January to December 2010 and were eligible if they were discharged from adult hospital services on HPN. Patients were excluded if they were unable to complete the questionnaire (either self-administered or at an interview) because of mental impairment.

Quality of life measure and data collection procedure

The HPN-QOL ${ }^{\odot}$ questionnaire was developed as a treatment specific instrument for the assessment of QOL in patients treated with HPN. It has been translated into Danish, Dutch, French, German, Italian, Polish and Spanish, using forward-backward methodology (16). The French translation was adapted for use in Belgium and French-speaking Canada and the English version adapted for use in the US and Canada. Psychometric small-sample validation of the English version confirmed the scale structure of the questionnaire (17).

The questionnaire contains 7 multi-item functional scales and 1 single-item functional scale, as well as 6 multi-item and 3 single-item symptom scale (17). The functional scales include General Health (GH), Ability to Holiday or Travel $(\mathrm{HT})$, Coping (CO), Physical Function (PF), Ability to Eat and Drink (ED), Employment (EM), Sexual Function (SX), and Emotional Function (EF); for these scales, a high score indicates a high level of functioning. The symptom or problem scales, in which a high score represents high 
severity or more problems, include Body Image (BI), Immobility (IM), Fatigue (FA), Sleep Pattern (SP), Gastrointestinal Symptoms (GI), other Pain (PA), Presence or Absence of a Stoma (ST), Financial Issues (FI), and Weight (WT). Two questions relate to nutrition teams and the availability of an ambulatory pump for infusion of HPN, in which a high score represents a good outcome. The questionnaire concludes with three 0-10 numerical rating scales (NRS) where high scores indicate high QOL. The first is a global QOL question and the other two respectively assess the effect of the underlying illness and of the HPN on overall QOL. The complete English version of the questionnaire can be found in the appendix of a previously published paper (17).

The questionnaire was self completed by the patients, either at a scheduled outpatient visit or at home after mail delivery.

Socio-demographic and clinical data including age, gender, educational level, marital and employment status, underlying disease, reason for HPN (life prolonging, quality of life improving or maintaining), duration of HPN, characteristics of the HPN program (day of infusion per week and hours of individual infusion) and functional status, were collected by the treating clinicians.

\section{Statistical analysis}

The HPN-QOL ${ }^{\odot}$ was scored according to scoring rules previously reported (17). When more than $50 \%$ of items in a scale or for the whole questionnaire were missing, the scale score or the questionnaire were dropped from analysis on a patient basis; when the number of missed items was $\leq 50 \%$ for a single scale, the mean of the completed items was used for simple imputation. Scores were rescaled to range from 0 to 100 and, to further improve readability, made uniform inasmuch as high scores indicate "good 
condition" in all scales (i.e. high function/good status as well as low symptom or problem intensity).

Psychometric analyses (Aim 1 of the study) evaluated the following aspects: data completeness, convergent /discriminant validity and internal-consistency reliability. Data completeness was measured by the percentages of missing scale scores. Convergent and discriminant validity were assessed through multitrait-scaling analysis (18) which explores the relationships of each item and the hypothesized scales. Convergent validity indicates a relevant correlation between an item and the scale to which it belongs. Correlations were corrected for overlap. Pearson correlation coefficients $\geq 0.4$ support convergent validity (18). Discriminant validity is supported whenever a correlation between an item and its hypothesized scale is higher than the correlation with the other scales. Internalconsistency reliability of multi-item scales was measured by Cronbach's alpha; alpha values above 0.7 are generally regarded as acceptable for group comparison (18). Psychometric analyses were performed on the overall sample and within the three largest language subsamples: English, French and Italian. Items not fitting with the predefined psychometric criteria on the overall sample were candidates for dropping or modification.

Aims 2 and 3 of the study were addressed with the use of a multivariable linear regression models in which the overall QOL assessment identified by the item 44 (how has your QOL been in the last week?) was the dependent variable. In a first analysis ("main model") the following variables were considered as predictors: HPN treatment duration (classified as short or long using a 24-month cut-point), age (continuous covariate), gender, living status, functional status and presence of a stoma. Language and underlying disease (categorical covariates) were modelled in the regressions using dummy variables. Stepwise backwarddeletion of non-significant regression covariates was used. This analysis was carried out in 
the set of 451 records with complete information. A second analysis ("extended model") was carried out in a set of 424 records that in addition contained a number of HPN details (indication, type of supply, days and hours of infusion). Although of clinical interest, these features are likely to reflect treatment decisions that had been based on patient and disease characteristics, and may thus originate some degree of confounding. Therefore, we followed a "two-step" strategy in which the first modelexplored prognostic effects of patient and disease characteristics, and the second included the effect of treatment details while adjusting for the other factors. Results are reported in terms of estimated regression coefficients (beta), corresponding 95\% confidence limits (95\% CLs) and overall $p$ values at the Wald's test, respectively for the main and extended models. The conventional twosided $5 \%$ level was chosen as the threshold of statistical significance. Statistical analyses were carried out with SAS (version 9.2, SAS Institute, Cary, NC) and R software (version 3.1.1, R Foundation for Statistical Computing, Vienna, Austria). 


\section{Results}

\section{Patient characteristics}

Six hundred and ninety-nine patients accepted to participate into the study and returned the questionnaire. Statistical analyses included 691 patients, after excluding eight questionnaires with more than $50 \%$ missing items.

More patients were female (61.6\%) than male, with a median age of 54 years (range, $17-$ 94) and with a varied geographical distribution (Table 1); $65.7 \%$ were either married or living with a partner and 95 (17\%) were living alone; most patients (92.2\%) had received at least compulsory school education. The underlying disease leading to CIF and HPN included 158 (26.3\%) Crohn's disease, 105 (17.4\%) motility disorders, 102 (16.9\%) mesenteric ischaemia, 47 (7.8\%) radiation enteritis, 38 (6.3\%) cancer, 152 (25.3\%) 'other'; 89 had missing diagnoses. The reason for HPN was to prolong life in 230 patients (45.3\% of total), to improve QOL in 175 (34.4\%) and to maintain QOL in 103 (20.3\%) (remaining data was missing). Duration of HPN infusion was $<2$ years in around one third of patients and $>10$ years in $26.4 \%$. Regarding functional status, $170(29.7 \%)$ of patients required some or total help.

Despite various reminders to participating centres, many socio-demographic and clinical data collection forms were not returned thus resulting in missing data.

\section{Psychometric evaluation of the $H P N-Q O L^{\odot}$}

Preliminary multitrait-scaling and internal consistency analyses indicated a bad fit of items 4 (burden of HPN), 20 (ability to socialize), 30 (nausea and vomiting) and 41 (bowel 
movements) with respect to the original questionnaire structure. These items were therefore excluded from their respective scales (CO, PF, GI and NoST) and regarded as single item scales (Table 2). The two 0-10 NRS items assessing the effect of illness and the effect of HPN on global QOL showed $11 \%$ and $12 \%$ of missing data, respectively . These figures match with results from the previous validation study where patients reported a difficulty to distinguish between the effect of illness and of HPN on QOL (16). For these reasons the two items were dropped from the analysis.

Results of psychometric analyses carried out on the modified questionnaire structure are shown in Table 2. Most scale-specific average scores were consistently around 60 to 70 , with the exception of sexual function, holiday/travel, employment and physical function which scored below 50. Item level missing-value rates -not shown in Table 2- were low, ranging from $0 \%$ to $6 \%$, except for the two items related to sex (17\% and $20 \%$ missing). Accordingly, completeness was good for most scales (Table 2), the only exception being sexual function ( $17 \%$ of missing), likely because of sensitivity issues in this area for some patients. Lower boundaries of item-internal consistency ranges indicate that all items in the questionnaire showed a satisfactory correlation with their own scale $(\geq 0.4)$, with the only exception of items 42 ("difficulty with bowel movements") and 43 ("painful bowel movements") in the No-stoma scale (0.38 internal correlation). Item-discriminant validity correlation figures (Table 2) were also satisfactory for all the comparisons performed. QOL NRS in particular yielded a median correlation with other scales of 0.32 , data not reported in table (range $0.14-0.53,5$ correlations $>0.4$ ); given the content of the scale, fairly high values were expected and may be considered acceptable. Internal consistency reliability was good for most of the multi-item scales, with Cronbach's a coefficients generally higher 
than the 0.70 benchmark, or only slightly below the benchmark for EM ( $\alpha=0.65), \mathrm{GI}$ $(\alpha=0.66)$, PA ( $\alpha=0.65)$ and noST $(\alpha=0.54)$.

Psychometric evaluation of the $\mathrm{HPN}^{-\mathrm{QOL}^{\odot}}{ }^{\odot}$ in the different English, French and Italian language patient sub-groups (Supplementary Tables A1, A2 and A3) provided results similar to those in the overall sample, thus confirming the good quality of these cultural adaptations.

\section{Investigation of QOL associated factors}

Results of the multivariable linear regression modelling are shown in Table 3. In the "main model" age, gender, functional status, presence of stoma and language failed to achieve statistical significance. Better overall QOL scores were observed in patients with HPN duration longer than 24 months compared to patients with shorter duration (beta=0.55, 95\%CL: $0.12-0.98 ; P=0.013)$. With the procedure described in the Methods Section, two clusters were detected for underlying disease in terms of outcome. Better QOL was observed in patients with Crohn's disease or mesenteric ischaemia compared to patients with other diseases (cancer, motility disorders, radiation enteritis or unspecified conditions). The corresponding beta coefficient was 0.65 (95\% CL:0.25 - 1.06; P=0.002). Patients living alone tended to be disadvantaged in terms of QOL outcome compared to patients not living alone (beta=-0.64, 95\%CL: $-1.18,-0.10 ; \mathrm{P}=0.021$ ). The whole profiles of standardized scale-specific scores according to HPN duration, underlying disease and living status are shown in Figures 1 to 3.

The "extended model", investigating the role of the HPN characteristics adjusted for the other factors showed a significant result only for HPN days of infusion per week. In 
particular, the negative coefficient denoted a worsening overall QOL for an increasing number of infusion days.

\section{Discussion}

This paper represents the final stage of developing the $\mathrm{HPN}-\mathrm{QOL}^{\odot}$, carried out on behalf of the HAN\&CIF Special Interest Group of ESPEN. It started with a review of the instruments used to assess QOL of adult patients with CIF receiving HPN and an evaluation of the state of art of this topic $(3,19)$ and then progressed with generation of QOL issues, production of a provisional questionnaire and its pre-testing (16). The scale structure of the questionnaire was initially tested for reliability and validity in a preliminary sample of 100 patients and showed positive results under the psychometric and clinical profile (17).

The present study went further by analyzing the psychometric properties of the questionnaire in a wider multi-language sample. In particular, multitrait-scaling and internal consistency analyses indicated a good fit with respect to the original questionnaire structure for most items. Exceptions were items 4 (burden of HPN), 20 (ability to socialize), 30 (nausea and vomiting) and 41 (bowel movements) which failed to upload to their respective scales and are better considered as separate single item scales. Also items 42 ("difficulty with bowel movements") and 43 ("painful bowel movements") in the No-stoma scale showed borderline internal correlation (0.38). The explanation for the poor consistency of these items is only hypothetical and probably reflects the heterogeneity of patients' population on HPN. For instance, patients with a low burden of disease-related symptoms may overestimate the burden related to the management of HPN, in contrast to 
patients requiring an intensive care for their primary disease/condition who may understand HPN as an invaluable help and willingly accept it. A similar explanation may apply for the items regarding "bowel movements" since some patients (ie those on HPN for chronic intestinal obstruction) may consider "frequent bowel movements" a positive event whereas for others (e.g. patients with short bowel syndrome) it might represent the premise for a further increase of the HPN volume, hours and/or days of infusion to compensate for the excessive fluid loss. Item discriminant validity analysis showed satisfactory correlation figures for all the comparisons performed; this confirms the nonoverlapping meaning of distinct scales. Finally psychometric evaluation of the HPN-QOL ${ }^{\odot}$ in the English, French and Italian language patient sub-groups provided results quite similar to those in the overall sample, confirming the psychometric equivalence of the questionnaire in the three language versions.

The "main model" of the multivariable linear regression showed that QOL score was significantly dependent on the type of the underlying disease, the duration of the HPN treatment and the living status. The "extended model" indicated that, when adjusted for factors identified by the "main model", the number of days of HPN per week has also a significant impact of QOL. Better QOL scores were observed in patients with Crohn's disease or mesenteric ischemia compared to patients with other kinds of disease (cancer, motility disorders, radiation enteritis or unspecified conditions). By showing better overall QOL in patients with longer HPN duration, this study is in agreement with the results of previous works $(20,21)$ indicating that patients are able to cope with their illness over time with a possible improvement in QOL. Although reasonable, this interpretation must be taken with caution considering that the cross-sectional study design does not allow the more direct assessment of time trends that would be possible with a longitudinal design. 
QOL is influenced by both the gastrointestinal illness and the effects of HPN treatment. To disentangle these effects, it would be necessary to prospectively study QOL scores in a cohort of patients who are candidates for HPN, prior to and after HPN. Such evidence cannot be achieved by a cross-sectional study like the present one. The finding that living alone is associated with worst QOL scores was also expected and can be explained by the complex technology of HPN administration that requires expertise in managing needles and bags with sterility as well as the invaluable role of an always available caregiver.

A number of studies have assessed QOL of patients requiring HPN but care must be taken when comparing their results with ours, as the majority of these studies relied on generic QOL tools that were neither tailored to nor validated in this patient population (19).

The actual role of HPN characteristics on QOL of patients with CIF, such as days of infusion per week and hours of infusion per day, is a key question. Indeed, HPN is the primary therapy of CIF and therefore is dependent on the characteristics of the underlying disease as well as pathophysiological mechanism of CIF (1). In a previous short term prospective follow up study on a small patient population, where QOL assessment was performed using the SF-36, a generic assessment tool, it was observed that the reduction of QOL was associated with an increase of HPN days of infusion per week. That result was considered to represent a deterioration of the intestinal failure (22). Nevertheless, the data of the present study indicate that, when adjusted for the major factors influencing QOL, the number of HPN infusion per week has a significant role. This agrees with data of a study on patients with short bowel syndrome, where QOL was assessed using a validated SBS-QoL ${ }^{T M}$ scale (23). In this cohort of patients, having the same underlying disease characteristics, the reductions in volume of HPN infusion (and therefore of hours and/or days of infusions) were associated with improvements in QOL scores. In 2014, the 
ESPEN HAN\&CIF group carried out an international multicentre study aimed to identify the top 3 most important outcome indicators (out of a list of 9 proposed), according to patients' perspectives (24). QOL was the third of the top 3 indicators, the incidence of catheterrelated infection and survival rate being the first two. Interestingly, for one of the nine outcome indicators (freedom and independence), there was a significant difference among patients categories based on HPN regimen (number of HPN day per week) and on HPN experience. Independence was rated more important for less experienced patients (HPN duration $<2$ years). Most of the less experienced patients received HPN on 7 days per week, whereas experienced patients had between 3 and 6 HPN days per week. Concerning the HPN regimen, patients with 6 or 7 HPN days consistently found independence important. This was not the case for patients with 5 HPN days or less per week (24). Patients were also asked to propose new indicators. Among those, two new indicators related to QOL were identified "keeping the problems related to my underlying disease as low as possible" and "maximizing HPN-free days" (24). Overall, our results and those from previous studies suggest that the burden of the underlying disease plays a primary role in determining QOL of patients on HPN for CIF and that, after optimizing the disease control, QOL could be further improved by reducing the HPN burden as much as possible.

There are a few limitations of this study. In the first place, information on sociodemographic and clinical data was not complete for as much as $35.5 \%$ of the patients originally entered into the study. This was due to administrative problem in some centres which performed only patient reported outcome assessment with $\mathrm{HPN}-\mathrm{QOL}^{\odot}$. Secondly, in spite of the considerable overall sample size, the number of patients for some language versions (German, Dutch, Danish, Polish and Spanish) was too small for distinct 
psychometric testing. More language specific data will be likely available if the HPN-QOL ${ }^{\odot}$ becomes embedded into routine clinical practice. The measurement of QOL should be included in the list of clinical quality indicators identified as part of the global attempt at raising the quality of clinical care (18); particularly since most patients are provided with HPN to either maintain or improve QOL. Finally, our cross-sectional study design could not address $\mathrm{HPN}-\mathrm{QOL}^{\odot}$ questionnaire's test-retest reliability and responsiveness to change, and these aspects will therefore have to be assessed in future studies.

In conclusion, this investigation responds to the lack of evidence regarding QOL assessment in patients undergoing HPN, and has the potential to integrate ESPEN guidelines. The results have both theoretical and practical implications. Many clinical services are inviting patients to respond to Patient Reported Outcome Measures including QOL and satisfaction with the service they receive. By embedding the assessment of QOL into routine clinical care clinicians will be provided with the necessary outcome evidence that ensures good patient centred care (25). Finally, the HPN-QOL ${ }^{\odot}$ here presented may also be used as a research tool in clinical trials. 


\section{Statement of authorship}

JPB designed the $\mathrm{HPN}-\mathrm{QOL}^{\odot}$ questionnaire and drafted the manuscript; $\mathrm{DG}, \mathrm{CB}$ and $\mathrm{LM}$ performed data analysis and contributed to manuscript writing; FB and LP contributed to manuscript writing. All authors executed the study and reviewed the manuscript. PMF was the study statistician.

\section{Acknowledgements}

All authors wish to thanks the patients of their respective countries and Ann Bradley (retired) Intestinal Failure Unit, Salford Royal Hospital, Manchester, UK.

\section{Conflict of interest declaration}

The authors declare that they have no competing interests.

\section{Funding sources}

This study was funded by an ESPEN Research Network Grant awarded in 2009. 


\section{References}

1. Pironi L, Arends J, Baxter J, Bozzetti F, Peláez RB, Cuerda C, Forbes A, Gabe S, Gillanders L, Holst M, Jeppesen PB, Joly F, Kelly D, Klek S, Irtun Ø, Olde Damink SW, Panisic M, Rasmussen HH, Staun M, Szczepanek K, Van Gossum A, Wanten G, Schneider SM, Shaffer J; Home Artificial Nutrition \& Chronic Intestinal Failure.; Acute Intestinal Failure Special Interest Groups of ESPEN.. ESPEN endorsed recommendations. Definition and classifications of intestinal failure in adults. Clin Nutr. 2015 Apr;34(2):171-80

2. Pironi L, Arends J, Bozzetti F, Cuerda C, Gillanders L, Jeppesen PB, Joly F, Kelly D, Lal S, Staun M, Szczepanek K, Van Gossum A, Wanten G, Schneider SM; Home Artificial Nutrition \& Chronic Intestinal Failure Special Interest Group of ESPEN. ESPEN guidelines on chronic intestinal failure in adults. Clin Nutr. 2016 Apr;35(2):247-307

3. Baxter JP, Fayers PM, McKinlay AW. A review of the quality of life of adult patients treated with long-term parenteral nutrition. Clin Nutr 2006;25:543-553.

4. Huisman-de Waal G, Schoonhoven L, Jansen J, Wanten G, et al. The impact of home parenteral nutrition on daily life-a review. Clin Nutr 2007:26; 275-288.

5. Persoon A, Huisman-de Waal G, Naber TA. Impact of long-term HPN on daily life in adult. Clin Nutr 2005;24;304-313.

6. Huisman-de Waal G. Versleijen M. van Achterberg T. Jansen JB. Sauerwein H. Schoonhoven L. Wanten G. Psychosocial complaints are associated with venous access-device related complications in patients on home parenteral nutrition. JPEN J Parent Enteral Nutr 2011;5:588-595. 
7. Messing B, Crenn P, Beau P, Boutron-Ruault MC, Rambaud JC, Matuchansky C. Long-term survival and parenteral nutrition dependence in adult patients with the short bowel syndrome. Gastroenterology 1999;117: 1043-1050.

8. Huismann-de Waal G, Bazelmans E, van Achterberg T, Jansen J, Sauerwein H, Wanten G, Schoonhoven L. Predicting fatigue in patients using home parenteral nutrition. International Journal of Behavioral Medicine 2011 18(3):268-76.

9. Baxter J, Gillanders L, Angstmann K, Staun M, O'Hanlon C, Smith T, Joly F, Thul P, Jonkers C, Gardiner K, Klek S, Cuerda C, Magambo W, Pironi L. Home parenteral nutrition (HPN): an international benchmarking exercise. E-SPEN Journal 7 (2012) e211-e214

10. Vantini I, Benini L, Bonfante F, Talamini G, Sembenini C,Chiarioni G, Maragnolli O, Benini F Capra F. Survival rate and prognostic factors in patients with intestinal failure. Digestive and liver disease: Official Journal of the Italian Society of Gastroenterology and the Italian Association for the Study of the Liver 2004; 36(1): 46-55.

11. Scolapio JS, Fleming CR, Kelly DG , Wick DM, Zinmeister AR. Survival of home parenteral nutrition-treated patients: 20 years of experience at the Mayo Clinic. Mayo Clinic Proceeding 1998;74(3): 217-222.

12. Lloyd DA, Zabron AA, Gabe SM. Chronic biochemical cholestasis in patients receiving home parenteral nutrition: prevalence and predisposing factors. Alimentary Pharmacology \& Therapeutics 2008; 27(7): 552-560.

13. Pironi L, Joly F, Forbes A, Colomb V, Lyszkowska M, Baxter J, Gabe S, Hébuterne X, Gambarara M, Gottrand F, Cuerda C, Thul P, Messing B, Goulet O, Staun M, Van Gossum A. Long term follow up of patients on Home Parenteral Nutrition in Europe: Implications for intestinal transplantation. Gut 2011:60;1. 
14. Hallum N, Baxter JP, McKinlay A, McKee RF. Home Parenteral Nutrition in Scotland: Outcome and seven year prospective follow up in a nationwide adult population. Clin Nutr 2012 e-SPEN Journal e30-e34.

15. Staun M, Pironi L, Bozzetti F, Baxter JP, Forbes A, Joly F, Jeppesen P, Moreno J, Hébuterne X, Pertkiewicz M, Mühlebach S, Shenkin A, Van Gossum A. ESPEN Guidelines on Parenteral Nutrition: Home Parenteral Nutrition (HPN) in adult patients. Clin Nutr 2009;28:467-479.

16. Baxter JP, Fayers PM, McKinlay AW. The development and translation of a treatment-specific quality of life questionnaire for adult patients on home parenteral nutrition. e-SPEN, the European e-Journal of Clinical Nutrition and Metabolism, 3(1), e22-e28.

http://www.journals.elsevierhealth.com/periodicals/yeclnm/article/S1751-4991

17. Baxter JP, Fayers PM, McKinlay AW. The clinical and psychometric validation of a questionnaire to assess the quality of life of adult patients treated with long term parenteral nutrition. JPEN 2010;34:131-142.

18. Hays RD, Hayashi T, Carson S. Users Guide for the Multitrait Analysis Program MAP), Santa Monica, CA: RAND; 1988.

19. Baxter JP, Fayers PM, McKinlay AW. A Review of the instruments used to assess quality of life of adult patients with chronic intestinal failure receiving parenteral nutrition at home. British Journal of Nutrition 2005; 94:633-638.

20. Winkler MF, Wetle T, Smith C, Hagan E, O'Sullivan Maillet J, Touger-Decker R. The meaning of food and eating among home parenteral nutrition-dependent adults with intestinal failure: a qualitative inquiry. Journal of the American Dietetic Association 2010:110; 1676-83. 
21. Winkler MF, Hagan E, Wetle T, Smith C, Maillet JO, Touger-Decker R. An exploration of quality of life and the experience of living with home parenteral nutrition. JPEN 2010; 34:395-407.

22. Pironi L, Paganelli F, Mosconi P, Morselli-Labate AM, Spinucci G, Merli C, Guidetti M, Miglioli M. The SF-36 instrument for the follow-up of health-related quality-of-life assessment of patients undergoing home parenteral nutrition for benign disease. Transplant Proc. 2004 Mar;36(2):255-8. PubMed PMID: 15050126.

23. Jeppesen PB, Pertkiewicz M, Forbes A, Pironi L, Gabe SM, Joly F, Messing B, Loth S, Youssef NN, Heinze H, Berghöfer P. Quality of life in patients with short bowel syndrome treated with the new glucagon-like peptide-2 analogue teduglutide-analyses from a randomised, placebo-controlled study. Clin Nutr. 2013 Oct;32(5):713-21. doi: 10.1016/j.clnu.2013.03.016. Epub 2013 Mar 28. PubMed PMID: 23587733.

24. Dreesen M, Pironi L, Wanten G, Szczepanek K, Foulon V, Willems L, Gillanders L, Joly F, Cuerda C, Van Gossum A. Outcome Indicators for Home Parenteral Nutrition Care: Point of View From Adult Patients With Benign Disease. JPEN J Parenter Enteral Nutr. 2015 Sep;39(7):828-36. doi: 10.1177/0148607114536926. Epub 2014 Jun 10. PubMed PMID: 24917517.

25. Baxter JP, Moreno Villares JM. Home parenteral nutrition: quality of life and psychosocial issues. In Bozzetti F ,Staun M and Van Gossum A eds. in Home Parenteral Nutrition CAB International, 2015, II edition : pp 381-394 
Table 1: Socio-demographic and clinical patient-characteristics

\begin{tabular}{|c|c|c|}
\hline & $\mathbf{N}$ & $\%$ \\
\hline Overall & 691 & 100.0 \\
\hline \multicolumn{3}{|l|}{ Gender } \\
\hline Female & 348 & 61.6 \\
\hline Male & 217 & 38.4 \\
\hline Missing & 126 & - \\
\hline \multicolumn{3}{|l|}{ Age, years } \\
\hline Median (range) & \multicolumn{2}{|c|}{$54(17-94)$} \\
\hline \multicolumn{3}{|l|}{ Marital status } \\
\hline Married/with partner & 341 & 65.7 \\
\hline \multicolumn{3}{|l|}{ Separated/divorced/widow } \\
\hline ed & 55 & 10.6 \\
\hline Single & 123 & 23.7 \\
\hline Missing & 172 & - \\
\hline \multicolumn{3}{|l|}{ Living status } \\
\hline Alone & 95 & 17.5 \\
\hline With family & 413 & 76.2 \\
\hline With other adults & 34 & 6.3 \\
\hline Missing & 149 & - \\
\hline \multicolumn{3}{|l|}{ Education } \\
\hline Less than compulsory & 35 & 7.8 \\
\hline Compulsory school & 189 & 42.4 \\
\hline Post compulsory & 155 & 34.8 \\
\hline University & 67 & 15.0 \\
\hline Missing & 245 & - \\
\hline \multicolumn{3}{|l|}{ Employment } \\
\hline Student & 19 & 4.3 \\
\hline Unemployed & 107 & 23.9 \\
\hline Homemaker & 43 & 9.6 \\
\hline Self employed & 7 & 1.6 \\
\hline Part time & 51 & 11.4 \\
\hline Full time & 60 & 13.4 \\
\hline Retired & 135 & 30.2 \\
\hline Other & 25 & 5.6 \\
\hline Missing & 244 & - \\
\hline \multicolumn{3}{|l|}{ Underlying Disease } \\
\hline Cancer & 38 & 6.3 \\
\hline Crohn's disease & 158 & 26.3 \\
\hline 25 & & \\
\hline
\end{tabular}


$\begin{array}{lll}\text { Mesenteric ischaemia } & 102 & 16.9\end{array}$

$\begin{array}{lll}\text { Motility disorders } & 105 & 17.4\end{array}$

Radiation Enteritis

$47 \quad 7.8$ 
Table 1 (continued)

\begin{tabular}{|c|c|c|}
\hline & $\bar{N}$ & $\%$ \\
\hline Other & 152 & 25.3 \\
\hline Missing & 89 & - \\
\hline $\begin{array}{l}\text { Predominant indication } \\
\text { HPN }\end{array}$ & for & \\
\hline Short gut & 346 & 60.8 \\
\hline Fistula & 12 & 2.1 \\
\hline Obstruction & 122 & 21.4 \\
\hline Other & 89 & 15.7 \\
\hline Missing & 122 & - \\
\hline \multicolumn{3}{|l|}{ HPN duration } \\
\hline 1-2 months & 9 & 1.5 \\
\hline 3-12 months & 93 & 15.5 \\
\hline 13-24 months & 95 & 15.8 \\
\hline $25-60$ months & 119 & 19.9 \\
\hline $61-120$ months & 125 & 20.9 \\
\hline more than 120 months & 158 & 26.4 \\
\hline Missing & 92 & - \\
\hline \multicolumn{3}{|l|}{ HPN supply } \\
\hline Total & 165 & 29.4 \\
\hline Supplemental & 397 & 70.6 \\
\hline Missing & 129 & - \\
\hline \multicolumn{3}{|c|}{ HPN days of infusion per week } \\
\hline Median (range) & \multicolumn{2}{|c|}{$5.6(2-7)$} \\
\hline Missing & \multicolumn{2}{|c|}{128} \\
\hline \multicolumn{3}{|l|}{ HPN hours of infusion per day } \\
\hline 2-11 hours & 190 & 31.8 \\
\hline $12-13$ hours & 290 & 48.5 \\
\hline More than 13 hours & 118 & 19.7 \\
\hline Missing & 93 & \\
\hline \multicolumn{3}{|l|}{ Functional status } \\
\hline Independent & 425 & 70.3 \\
\hline Some help & 143 & 23.6 \\
\hline Total help & 37 & 6.1 \\
\hline Missing & 86 & - \\
\hline \multicolumn{3}{|l|}{ Country } \\
\hline United Kingdom & 127 & 18.4 \\
\hline Italy & 117 & 16.9 \\
\hline United States & 81 & 11.7 \\
\hline
\end{tabular}


France

Netherlands

Spain

Germany

Belgium
$76 \quad 11.0$

$64 \quad 9.3$

$43 \quad 6.2$

$40 \quad 5.8$

$35 \quad 5.1$

Table 1 (continued)

\begin{tabular}{lll}
\hline & N & \% \\
\hline Poland & 35 & 5.1 \\
Canada & 32 & 4.6 \\
Denmark & 20 & 2.9 \\
New Zealand & 12 & 1.7 \\
Australia & 9 & 1.3 \\
Missing & - & - \\
\hline
\end{tabular}

Abbreviations:

HPN: home parenteral nutrition 
Table 2: Results of Item Scaling and Reliability: overall sample ( $N=691)$

\begin{tabular}{|c|c|c|c|c|c|c|c|}
\hline Scale & $\mathrm{k}^{\mathrm{b}}$ & $\underline{\text { Mean }}$ & SD & $\begin{array}{l}\text { Missing } \\
\%\end{array}$ & $\begin{array}{l}\text { Item-Internal } \\
\text { Consistencyc }\end{array}$ & $\begin{array}{l}\text { Item-Discriminant } \\
\text { Validity }^{d}\end{array}$ & Reliabilitye \\
\hline Immobility (IM) & 5 & 68 & 25 & 1 & $0.50-0.73$ & $0.03-0.49$ & 0.84 \\
\hline Physical Function (PF) & 3 & 48 & 26 & 6 & $0.52-0.69$ & $-0.04-0.59$ & 0.78 \\
\hline Ability to Holiday/Travel (HT) & 2 & 34 & 26 & 5 & 0.83 & $0.01-0.30$ & 0.91 \\
\hline Coping (CO) & 2 & 58 & 27 & 2 & 0.57 & $0.07-0.57$ & 0.73 \\
\hline Ability to Eat/Drink (ED) & 2 & 62 & 26 & 4 & 0.55 & $-0.04-0.36$ & 0.71 \\
\hline Sexual Function (SF) & 2 & 22 & 25 & 17 & 0.63 & $-0.07-0.25$ & 0.77 \\
\hline Body Image (BI) & 2 & 66 & 33 & 1 & 0.76 & $-0.01-0.44$ & 0.86 \\
\hline Fatigue (FA) & 2 & 52 & 31 & 0 & 0.84 & $0.01-0.55$ & 0.91 \\
\hline Gastrointestinal Symptoms (GI) & 2 & 64 & 29 & 4 & 0.49 & $-0.07-0.29$ & 0.66 \\
\hline Pain (PA) & 2 & 64 & 29 & 0 & 0.48 & $0.04-0.41$ & 0.65 \\
\hline Presence of Stoma (ST) & 2 & 70 & 29 & 3 & 0.70 & $-0.05-0.39$ & 0.82 \\
\hline Absence of Stoma (NoST) & 2 & 79 & 26 & 5 & 0.38 & $-0.01-0.38$ & 0.54 \\
\hline Sleep Pattern (SP) & 1 & 60 & 35 & 0 & - & $0.01-0.35$ & - \\
\hline Financial Issue (FI) & 1 & 75 & 32 & 6 & - & $-0.09-0.26$ & - \\
\hline Burden of HPN (item 4) & 1 & 66 & 30 & 1 & - & $0.05-0.50$ & - \\
\hline Ability to socialize (item 20) & 1 & 50 & 33 & 2 & - & $-0.10-0.23$ & - \\
\hline Nausea and vomiting (item 30) & 1 & 74 & 32 & 0 & - & $0.06-0.35$ & - \\
\hline $\begin{array}{l}\text { Bowel movements (no stoma) (item } \\
41 \text { ) } \\
\text { OOL Numeric Rating Scale }\end{array}$ & 1 & 46 & 33 & 5 & - & $-0.29-0.19$ & - \\
\hline (NRS) & 1 & 58 & 21 & 3 & - & $0.14-0.53$ & - \\
\hline
\end{tabular}


b Number of items ${ }^{\mathrm{c}}$ Range of correlations between items in the scale
${ }^{\mathrm{d}}$ Range of correlations between each item in the scale and other scale

e Internal-consistency reliability (Cronbach's alpha) 
Table 3: Multivariable regression modelling used to investigate the factors associated with overall QOL

Category (reference)

Main model $(\mathrm{N}=451) \S$

Age, years

IQ range: $44-64$

Gender

Male (female)

Underlying disease Crohn's/Ischaemia

(other)

Living status
Alone (not alone)
$-6.4(-11.8--1.0) \quad 0.021$
$-6.4(-11.8--1.0) \quad 0.021$

Functional status

Some help

(indepedent)

Total help

(independent)

Stoma

$$
\text { Yes (no) }
$$

HPN duration

$$
\text { Long (short) }
$$

Language

French (English)

Italian (English)

Other (English)

$$
\begin{array}{ll}
-0.9(-3.6-1.9) & 0.543 \\
0.4(-3.7-4.4) & 0.862
\end{array}
$$

$6.5(2.5-10.6) \quad 0.002$
$1.6(-6.8-9.9)$

$-3.7(-7.7-0.3) \quad 0.073$

$5.5(1.2-9.8) \quad 0.013$

$3.6(-2.1-9.3) \quad 0.053$

$-3.1(-8.9-2.6)$

$3.8(-1.6-9.2)$

Extended model $(\mathrm{N}=424) \S$

Indication

Obstruction (short gut) $\quad-1.3(-7.7-5.2) \quad 0.468$

31 
Other/fistula (short gut)

HPN supply

Total (supplemental)

HPN days of infusion per week

IQ range: 4-7

HPN hours of infusion per day

$12-13(<12)$

$>13(<12)$

$\S$ Main model: HPN characteristics excluded because dependent on the underlying disease

$\S$ Extended model: assessment of the HPN characteristics

adjusted for the remaining factors

Abbreviations:

QOL: quality of life

$\mathrm{Cl}$ : confidence interval

IQ: interquartile

HPN: home parenteral nutrition

$$
-4.1(-10.7-2.5)
$$

$$
2.2(-2.8-7.2) \quad 0.392
$$$$
-4.7(-8.9--0.5) \quad 0.028
$$

$-5.1(-10.5-0.3) \quad 0.140$

$-5.7(-12.2-0.8)$ 
Figure 1 Profiles of standardized scale scores according to HPN duration, underlying disease and living status

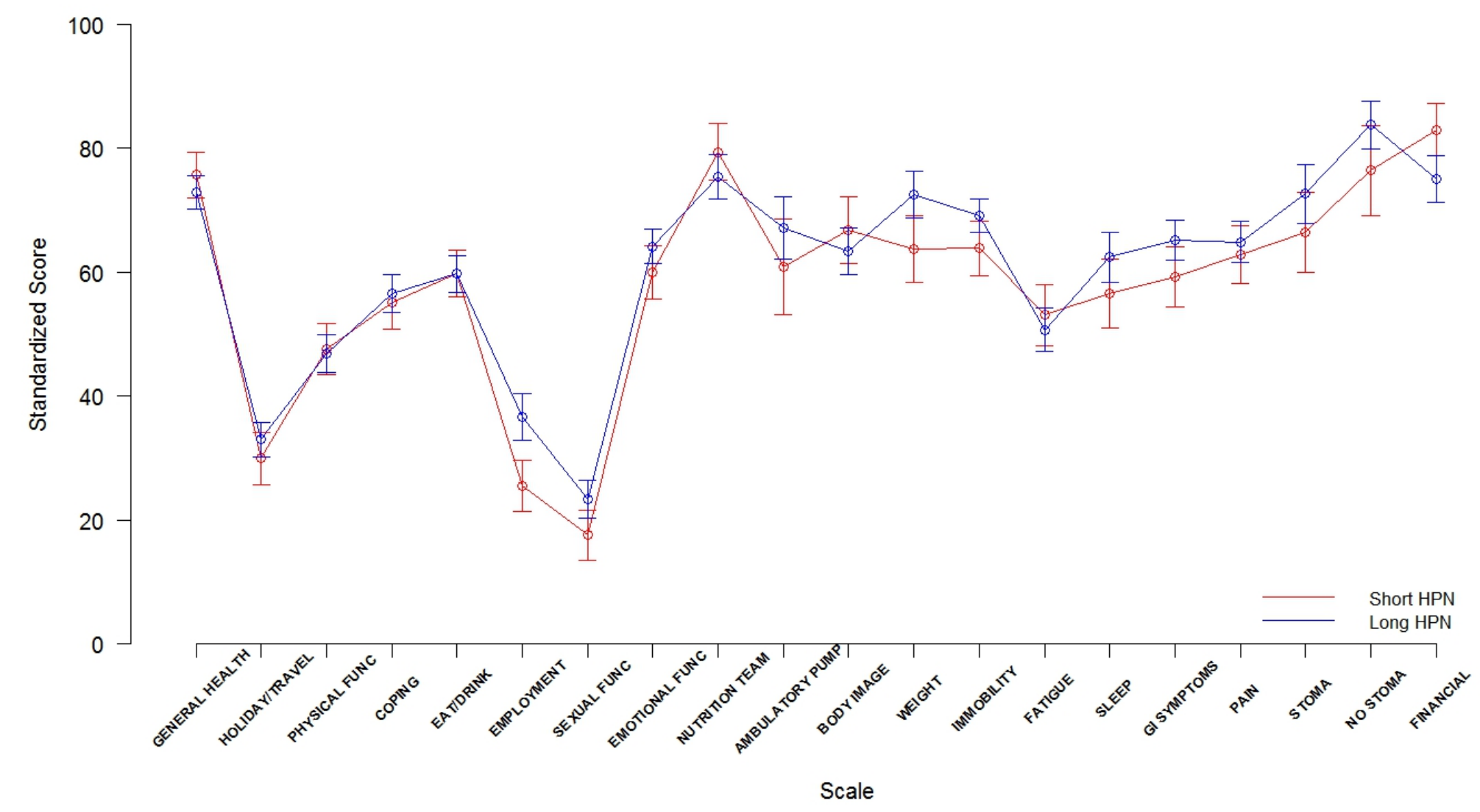


Figure 2 profiles of standardized scale scores according to underlying disease

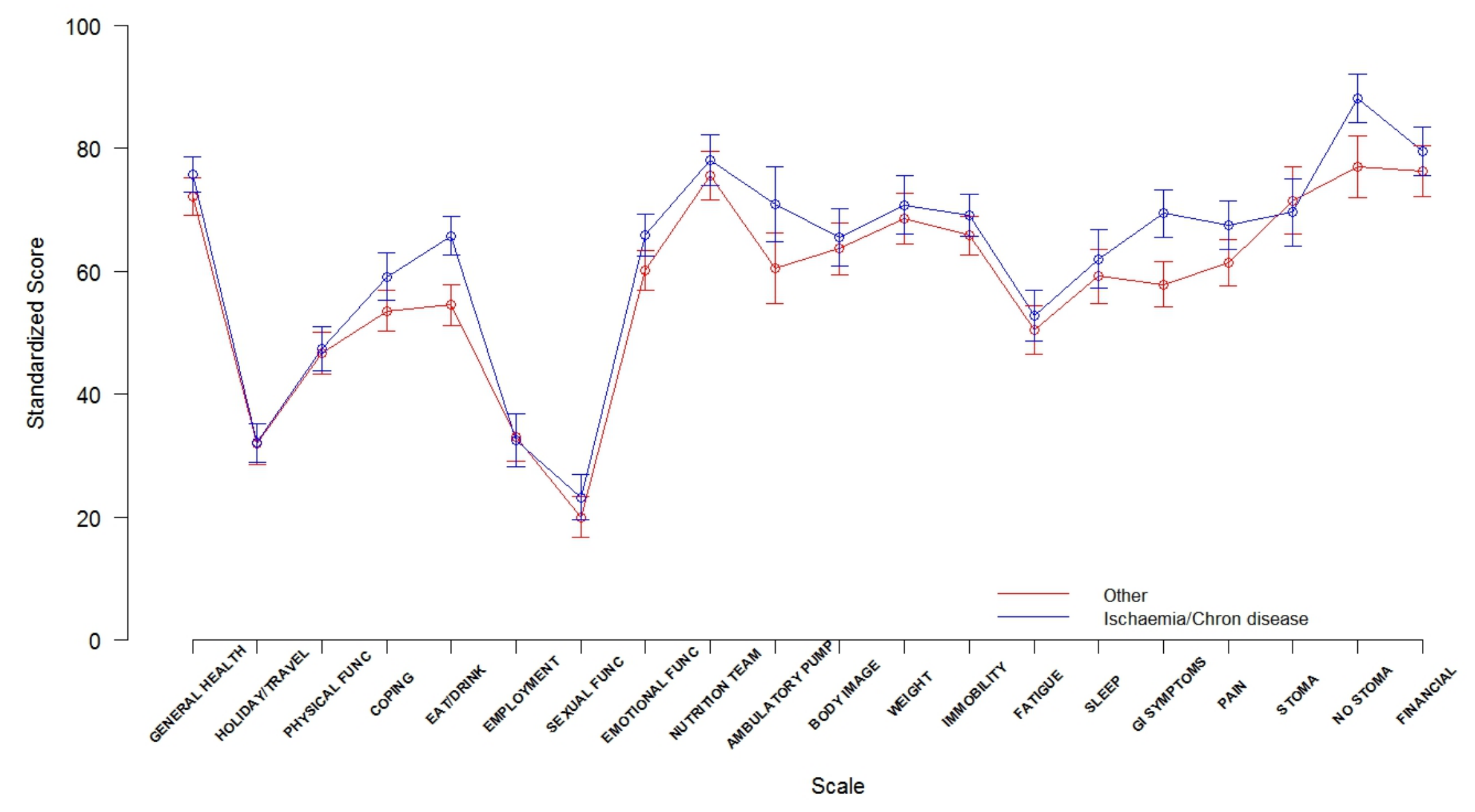


Figure 3 Profiles of standardized scale scores according to living status

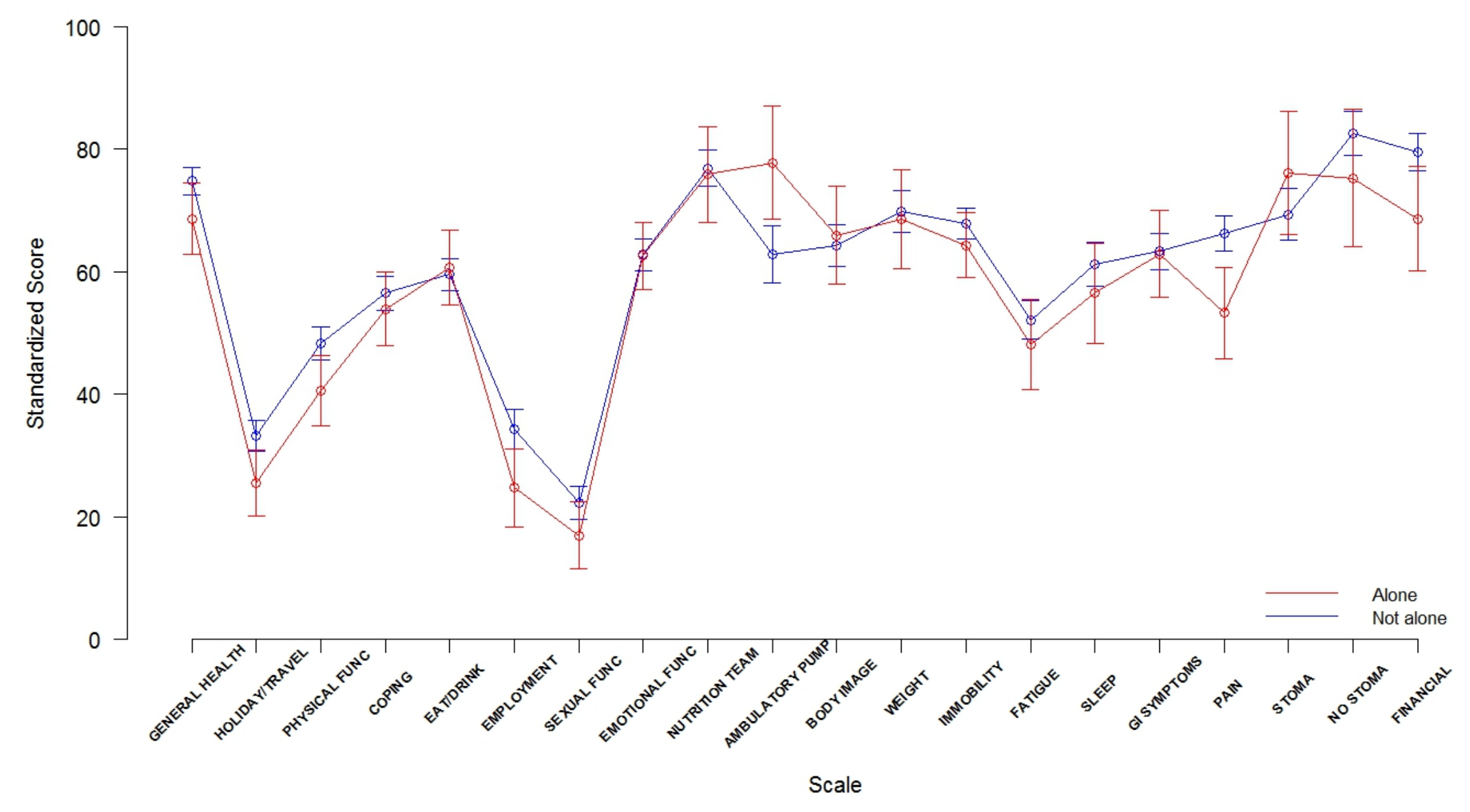


Supplementary Table A1: Item Scaling and Reliability: English language sample(N = 229)

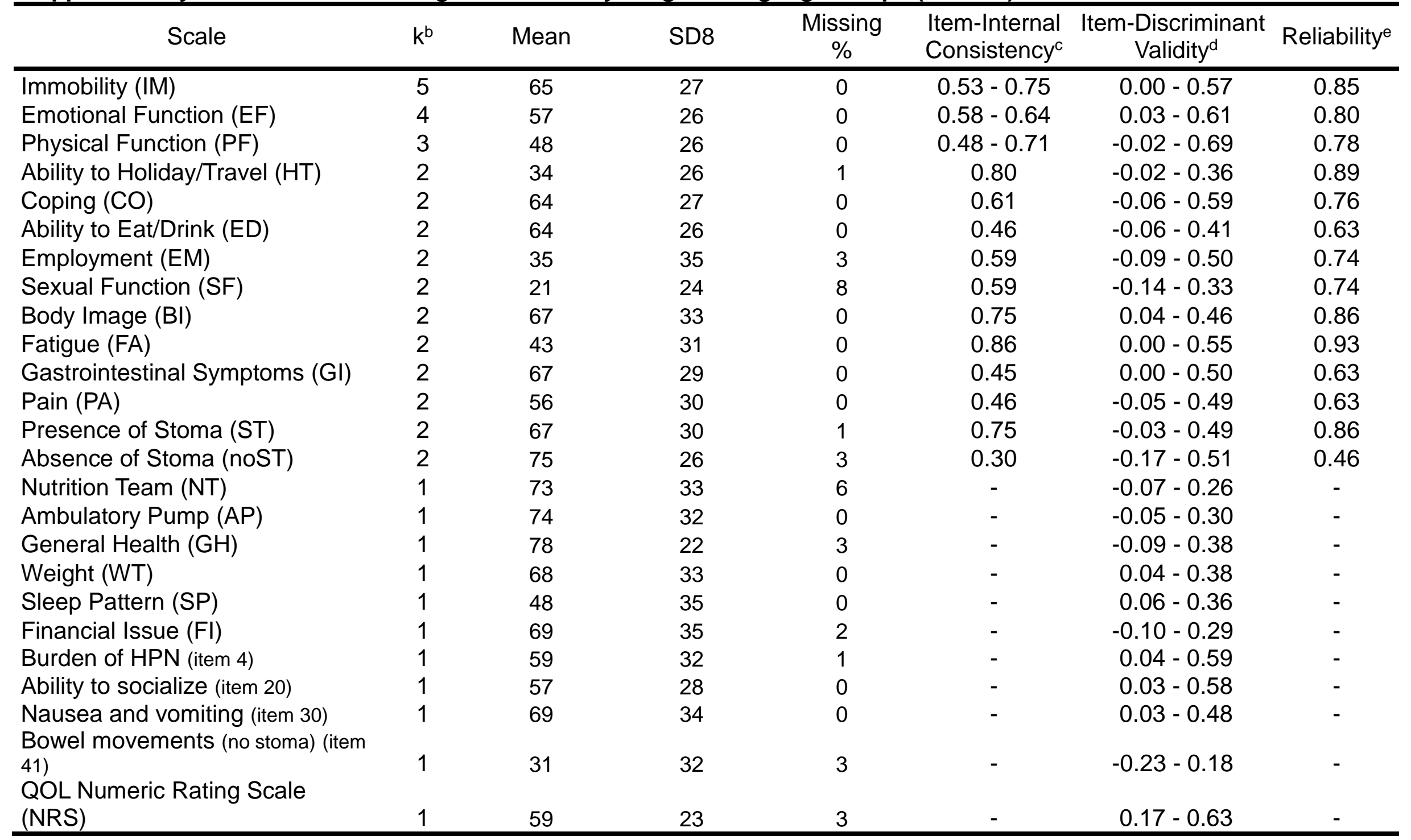


b Number of items ${ }^{\mathrm{c}}$ Range of correlations between items in the scale
${ }^{\mathrm{d}}$ Range of correlations between each item in the scale and other scale

e Internal-consistency reliability (Cronbach's alpha) 
Supplementary Table A2: Results of Item Scaling and Reliability: French language sample $(\mathrm{N}=143)$

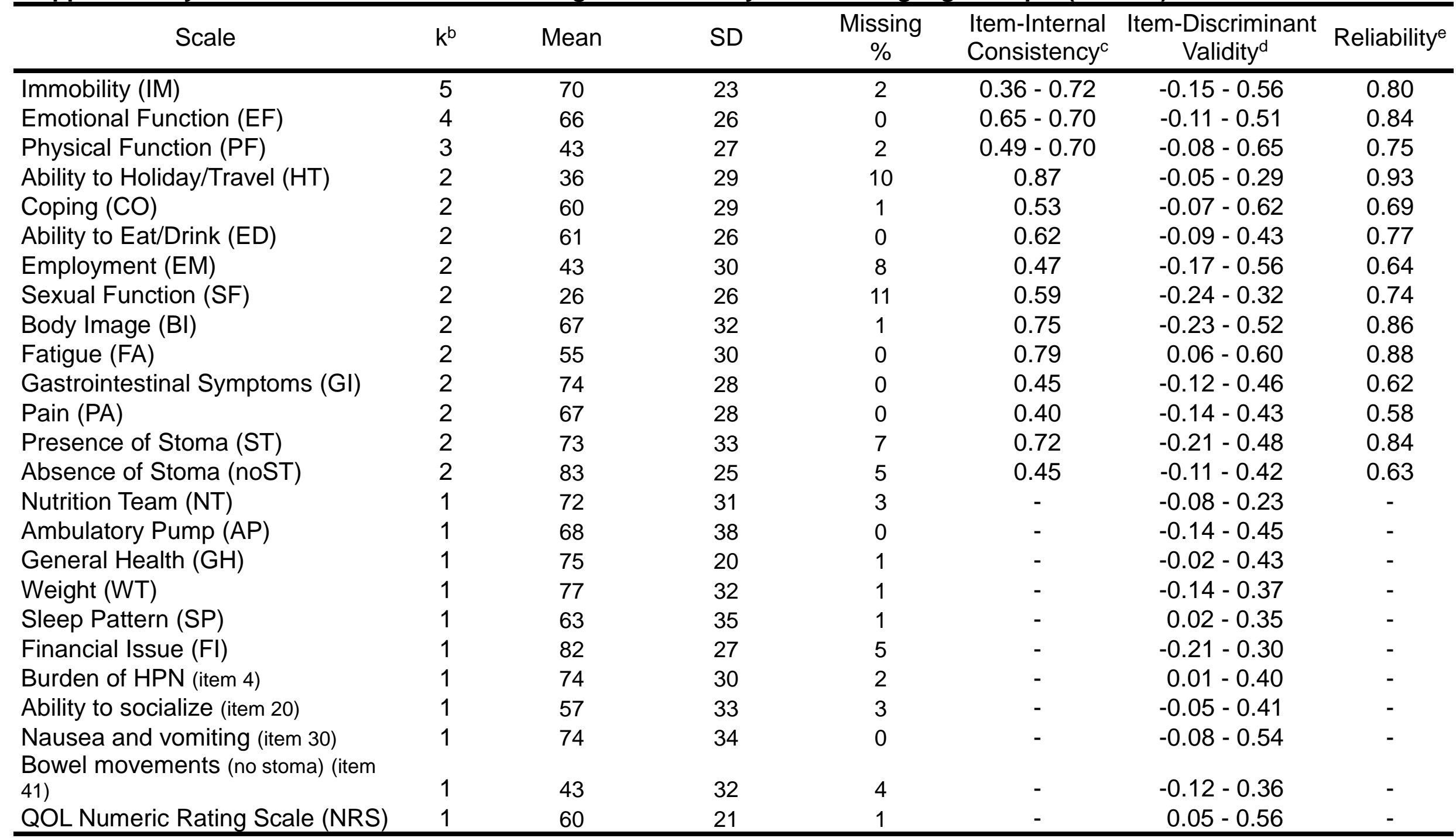

${ }^{\mathrm{b}}$ Number of items 


\begin{abstract}
${ }^{c}$ Range of correlations between items in the scale
d Range of correlations item between each item in the scale and other scales

e Internal-consistency reliability (Cronbach's alpha)
\end{abstract}


Supplementary Table A3: Results of Item Scaling and Reliability: Italian language sample (N = 117)

\begin{tabular}{|c|c|c|c|c|c|c|c|}
\hline Scale & $\mathrm{k}^{\mathrm{b}}$ & Mean & SD & $\begin{array}{c}\text { Missing } \\
\%\end{array}$ & $\begin{array}{l}\text { Item-Internal } \\
\text { Consistency }^{c}\end{array}$ & $\begin{array}{l}\text { Item-Discriminant } \\
\text { Validity }^{\mathrm{d}}\end{array}$ & Reliability \\
\hline Immobility (IM) & 5 & 70 & 21 & 0 & $0.50-0.82$ & $-0.35-0.66$ & 0.85 \\
\hline Emotional Function (EF) & 4 & 62 & 25 & 0 & $0.52-0.72$ & $-0.25-0.53$ & 0.81 \\
\hline Ability to Holiday/Travel (HT) & 2 & 34 & 24 & 0 & 0.86 & $-0.30-0.42$ & 0.93 \\
\hline Coping (CO) & 2 & 48 & 23 & 5 & 0.28 & $-0.45-0.74$ & 0.44 \\
\hline Ability to Eat/Drink (ED) & 2 & 59 & 22 & 2 & 0.66 & $-0.50-0.50$ & 0.79 \\
\hline Body Image (BI) & 2 & 59 & 35 & 0 & 0.86 & $-0.09-0.52$ & 0.92 \\
\hline Fatigue (FA) & 2 & 64 & 25 & 0 & 0.85 & $-0.28-0.67$ & 0.92 \\
\hline Gastrointestinal Symptoms (GI) & 2 & 48 & 23 & 2 & 0.62 & $-0.46-0.17$ & 0.77 \\
\hline Pain (PA) & 2 & 71 & 28 & 0 & 0.59 & $-0.24-0.45$ & 0.75 \\
\hline Presence of Stoma (ST) & 2 & 72 & 25 & 5 & 0.58 & $-0.38-0.48$ & 0.74 \\
\hline Absence of Stoma (noST) & 2 & 78 & 30 & 3 & 0.59 & $-0.30-0.45$ & 0.70 \\
\hline Sleep Pattern (SP) & 1 & 71 & 32 & 0 & - & $-0.24-0.48$ & - \\
\hline Financial Issue (FI) & 1 & 80 & 31 & 12 & - & $-0.34-0.40$ & - \\
\hline Burden of HPN (item 4) & 1 & 70 & 27 & 0 & - & $-0.18-0.53$ & - \\
\hline Ability to socialize (item 20) & 1 & 32 & 34 & 5 & - & $-0.63-0.28$ & - \\
\hline Nausea and vomiting (item 30) & 1 & 84 & 25 & 0 & - & $-0.24-0.44$ & - \\
\hline $\begin{array}{l}\text { Bowel movements (no stoma) (item } \\
41 \text { ) } \\
\text { OOL Numeric Rating Scale }\end{array}$ & 1 & 59 & 32 & 3 & - & $-0.70-0.48$ & - \\
\hline (NRS) & 1 & 54 & 21 & 5 & - & $-0.18-0.57$ & - \\
\hline
\end{tabular}




\section{b Number of items \\ ${ }^{c}$ Range of correlations between items in the scale \\ ${ }^{d}$ Range of correlations item between each item in the scale and other scales \\ e Internal-consistency reliability (Cronbach's alpha)}




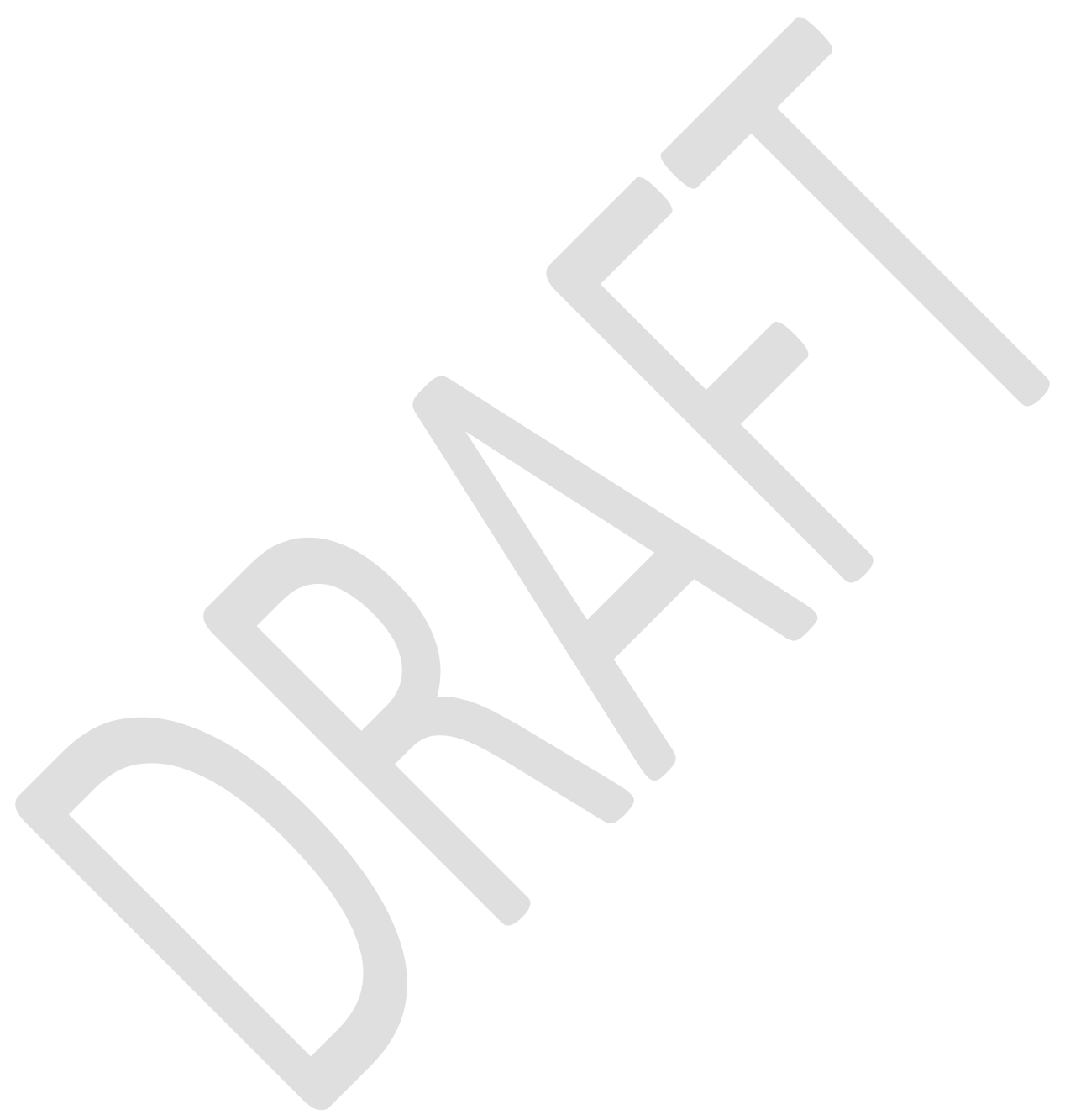

